ESJ Social Sciences

\title{
Impact of Internet on Academic Performance of University Students in Pakistan
}

\author{
Nimra Nawaz, PhD Candidate \\ Shanghai International Studies University, China
}

Doi:10.19044/esj.2021.v17n38p1

Submitted: 14 August 2021

Accepted: 28 October 2021

Published: 30 November 2021
Copyright 2021 Author(s)

Under Creative Commons BY-NC-ND

4.0 OPEN ACCESS

Cite As:

Nawaz N. (2021). Impact of Internet on Academic Performance of University Students in Pakistan. European Scientific Journal, ESJ, 17 (38), 1.

https://doi.org/10.19044/esj.2021.v17n38p1

\begin{abstract}
It is impossible to ignore the fact that the internet is the basic need of today's technological world. Different research shows that individuals across the globe are using information and communication technologies (ICTs) to get the most up-to-date information from the internet. Similarly, university students also spend a lot of time on the internet researching and collecting material relevant to their research topics. Although different research has been conducted on the usage of the internet in different countries, research about Pakistani students is still limited. The major goal of this research was to see how internet usage affects students' academic performance particularly when it comes to increasing their grades. The objective of this research was to determine the type of internet use and the impact of the internet on students' academic achievement. Arts faculty from the University of Punjab Pakistan was selected as the universe of the study and 5 departments of arts were selected by simple random sampling and a sample of 100 students was taken through systematic sampling. The study adopted a survey research design. A questionnaire was developed by the researchers as a tool for data collection. The data was analyzed statistically, which led to the acceptance of the alternative hypothesis. Statistical results are also presented and discussed, and implications for future research are also provided. According to the findings, internet use has a positive impact on student's academic achievement.
\end{abstract}

Keywords: Internet, students, academic performance, Pakistan 


\section{Introduction}

The first time the internet was introduced to Pakistan was in 1995 when Digicam launched its internet services in Karachi. Recently, there has been notable growth in internet usage. In Pakistan, information technology is a burgeoning industry with enormous potential. All information technologyrelated issues are closely monitored, regulated and overseen by the Ministry of Information and it is distributed and controlled by the Pakistani government. The Reports by the Economic and Social Commission for Asia and the Pacific, United Nations, 2002 showed that the communication system for Pakistan is also reliable. The country's information and technology system is growing fast, adopting the requirements for e-commerce and e-government. The growth of information technology in Pakistan has opened new business opportunities. The government of Pakistan is giving top priority to information technology systems in terms of both policy-making and allocation of resources.

The number of internet users in Pakistan skyrocketed in 2011 with over 20 million active subscribers. They are one of the top ten countries in the world with the highest internet penetration rate. It currently has the world's 27 th most users. During the fiscal year 2012-2013, the Pakistani government budgeted 4.6 billion rupees for I.T. related projects and focused on infrastructure, human resources, and digital solutions within the government parastatal. By the end of Pakistan's fiscal year 2017-2018 (June 30, 2018), the Telecom/IT industry income had reached USD 15.35 billion, the highest level in four years. The market income in 2016-17 was PKR 464.11 billion (which is nearly USD 3.43 billion). The market revenue increased steadily from PKR 439.52 billion to PKR 464.11 billion between 2012 and 2017, except for one year (2015). Foreign direct investment in Pakistan's telecom/IT sector has totaled USD 4.77 billion during the last five years. However, over the last two years, investment inflows have decreased.

The internet is also expanding the use of technology in education and communications (Warren et al., 1998). With the development of technology, such information is readily accessible with a mouse click. Undoubtedly, internet use has risen quickly throughout the country's education system, particularly tertiary. Higher education institutions and department students utilize the internet daily. Most higher education institutions have developed and implemented new and creative teaching methods. Research conducted by Laurillar (1992) shows that computer-based learning can increase understanding of theoretical and critical concepts. According to Hussain (2012), the internet's use in higher education has aided educational advancement and research, as well as promoted virtual relationships for sharing research findings. 
The explanation behind internet use for academic and research purposes originates from the advantage that individuals have, for example, free access to online journals, books, and other assets. Furthermore, the use of blended media is a similarly helpful use of the internet for study. Visual data is thought to have a higher influence on learning and memorizing than plain text. Images, graphics, animation, photos, slides, documentaries, and other graphical media have a superior graphical presentation than plain text. The use of multimedia and the internet give opportunities for all students to get knowledge about any particular subject in depth. Sometimes, a reference book is not generally accessible to students and they may experience issues getting to the books in the library but if the reference books for numerous subjects are available on the internet, students can easily access it.

We can see that the use of the internet is becoming more prevalent in our daily life particularly in the area of education. So, it is justified to investigate students' perceptions and comprehension of the availability and use of electronic hotspots for academic research and learning. The present study aims to explore the impact of the internet on the education system and students' academic performance. As a result, looking into how these students deal with using the internet to enhance their educational research and learning is relevant to the research. This also necessitates investigating the issues confronting students in this area as they relate to the use of the internet for indepth research and learning. The findings of this back-and-forth movement study are expected to contribute to the redesigning of exploratory inquiry results that will illuminate training and learning practice in cutting-edge instruction. This will also provide pupils living in this underserved area with a better knowledge of the application and importance of internet resources.

\section{Review of Literature}

One of the most significant successes in the field of information and technology was the introduction of internet use. The use of the internet has been a major drive to change the world into a global village. According to Asdaque et al. (2010) and Al-Rahmi et al. (2013), it is widely accepted that the internet has greatly influenced students' social lives and their academic achievements. For instance, Habes et al. (2018) researched the influence of internet use on students' academic performance. The research was done using a sample of 150 students equally distributed among three universities. The study implicated that internet use has a positive impact on students' academic performance. A study by Eguavoen (2016) showed that there was a strong correlation between ICT usage and the academic performance of students with visual impairment. The use of the internet provides students with opportunities to surf the internet and search for academic information as well as utilize social networking platforms as a medium of information exchange. Harrath and 
Alobaidy (2016) pointed out that many students expressed satisfaction with the use of social networking sites as a way to gather data or collect information for their studies. Desmal (2017) also indicated that the use of the internet and social networking platforms brings benefits and opportunities for students to support their learning process. However, it was also discovered that some university students have been using social media, paying more attention to platforms like Facebook, which negatively affected their academic performance.

According to studies by several authors, internet use has brought about a wide and rich knowledge base for university students (Ghasempour et al., 2014). For example, Laird and Kuh (2005) in their study found that the internet is very helpful for learning and teaching. The results demonstrate that there is a solid positive connection between utilizing data innovation for instructive purposes and association with successful instructive practices (Kirschner and Paas, 2001; Mwanza and Musyoka, 2018). The examination likewise upholds the previously mentioned outcomes that the internet has a special number of characteristics that can permit instructors at all levels to make and utilize new devices to present and customize the learning experience for their understudies. It is said that the internet has made it easy for students to easily get good and valid information about their subject. (Heather Kanuka, 2002; Kolikant., 2010) also found that online study is the greatest way to study through internet classes and lectures to get higher studies. For virtual university students, the internet's impact is extremely beneficial. This study looks into how teaching and learning principles can be applied in internetbased distance learning contexts. The research conducted by Yang et al. (2003) sheds light on the role of technology and its impact on student success in academic activities. The impact of social networking sites on academics was studied using data from 40 researchers. The findings show that primarily, these social platform factors are closely linked to college students' overall performance in class and online. Rabiu et al. (2016) have conducted a similar study regarding the influence of Mobile phone usage on students' academic performance. Most pupils' academic performance is negatively correlated with adverse circumstances. Second, advising and adversarial network variables are often beneficial determinants in determining academic performance, even though adversarial network variables have little effect on student performance in the cyber world. Friendship network volatility is not a significant factor in a student's academic success.

Social Networking has been around for several years as a way of communication between friends and family and has been a source of building relationships. With the increase in internet users for communication, social networking has become a household name. Some examples of social networking websites are Twitter, WhatsApp, and Facebook (Miller, 2020). 
Since social networking became a prominent online tool, various studies have been conducted to determine how it is affecting young people (Bryant et al., 2006; Shabir et al., 2014). In the early stages, it was believed that social networking sites would negatively influence adolescent communication. However, other researchers (Ahmed et al., 2011; Baruah and Hazarika, 2020), had a belief that technological communication was also going to benefit many youngsters, especially those with challenges in expressing their feelings and thoughts face-to-face. The argument, however, continues to be analyzed and it still remains a question which a lot of researchers want to be answered. Looking at some of the popular social networking sites, different conclusions can be reached about the reasons why these sites are popular with youngsters.

Online communication was introduced in the early 1990s in forms of communication platforms such as electronic mail and chat rooms (Peter \& Valkenburg, 2009). Other writers, like Dr. Norman Nie (Stanford University), had a belief that these online communication technologies could negatively influence adolescents' social lives as well as affect their sense of well-being (Flad, 2010; Dramanu and Balarabe, 2013). Several researchers on children and adults also alleged that internet use would lead to superficial online relationships. Researchers predict that instead of building on established physical relationships, many teenagers will use the internet only to meet with strangers. Reports by other researchers assumed that adults would spend most of their time on computers, which would greatly impact their social interactions and relationships in a negative way.

Merten \& Williams (2009) indicated that adolescent girls share information concerning their daily and personal lives more than boys do. Results from research that involved platforms such as MySpace, Xanga, and Facebook indicated that although most youngsters (13-17 years) use social networking sites for fun purposes, $55 \%$ of girls usually share personal issues such as relationship challenges, anxiety, and depression. Only $15 \%$ of their male counterparts volunteered personal information about themselves outside of their relationships, friendships, interests, and hobbies. Adolescents frequently use social media sites, according to the study, especially after a peer dies. They also use member profiles to help them through the grief process.

Social media can sometimes have negative consequences. They are likely to increase the number of cases of online victimization and cyberbullying. Cyberbullying is described as the use of online platforms to cause harm to other users of the internet. Cyberbullying takes many forms, including harassing emails, abusive instant chats, and harsh posts on social media platforms. Cyberbullying causes a variety of reactions in the targeted internet users, including low self-esteem, character defamation, feelings of belittlement, and, in rare cases, suicide. According to a national poll, approximately 13 million youngsters between the ages of 6 and 17 have been 
victims of cyber-bullying. According to studies, some adolescents take advantage of the internet because there is no face-to-face interaction, and so harass or harm other students (Mesch, 2009; Abaido, 2020).

Ever since social networking sites became popular, the conflict and trouble between parents and children have been on the increase (Greenfield \& Subrahmanyam, 2008; Mesch, 2018). Research shows that children with a strong sense of communication skills and who are close to their parents or guardians, do better in their bookwork. As juveniles are hooked on various forms of technology and the internet, their mode of communication changes because of the different abbreviations and acronyms they use during communication. The gap between them and their parents keeps increasing. Many parents find it difficult to understand their teenage children these days. It is very difficult to relate to their virtual world. This brings about peril in the home and, in most cases, leads to a barrier between the parents and the children, thereby affecting their grades in school.

By reviewing the above study, researchers found that although the usage of interment is helpful, as compared to other countries, there is very limited research conducted about Pakistani students. Thus, there is a need to research Pakistani students. Therefore, this paper explores the impact of the internet on the academic performance of Pakistani students. To achieve this intention, this study has two (2) fundamental objectives:

1. What is the nature of the use of the internet by Pakistani students?

2. To what extent has the use of the internet been instrumental in improving the academic performance of students (including improving grades)?

\section{Methodology \\ Research Design}

The study used a survey research strategy to try to address the research questions stated in the study. To gather data, quantitative research techniques have been employed since they allow for the measurement of variables and build numbers that represent the results. Accordingly, the research adopted a quantitative approach since it was built around a set of factors that could be quantified and evaluated using statistical methods. To evaluate the relationship between cause and effect, the researcher utilized quantitative techniques that employ statistics and statistical facts and figures which helps to determine the degree to which the factors studied influence the students' academic achievement. A quantitative survey that consists of the use of questionnaires was administered among 100 students. The questionnaire has 34 questions. Every question was measured by the level of cordial relationship between the use of the internet and academic performance. Few questions were open-ended and some were closed-ended due to the nature of questions. The questionnaire 
was divided into three parts by the researcher. The first part contained the demographic profile of the respondent. Second, one had questions about investigating the nature of internet usage. The third one had questions about the impact of the internet on academic performance. The researcher uses openended and closed-ended questions.

\section{The Selection Procedure for Participants}

This study's population is the University of Punjab's Arts Faculty students. Due to time constraints, we chose just the Arts faculty rather than all Punjab University faculties. There are 21 departments in the Arts faculty named as 1) Department of Sociology 2) Institute of Business Administration 3) Halley College of Commerce 4) Department of Women Study 5) Department of History 6) Department of Political Science7) Institute of Administrative Science 8)Department of Archaeology 9) Department of Economics 10)Department of English language \& literature 11) Department of French12) Department of Library \& Information sciences 13) Department of Mess Communication14) Department of Philosophy15)Department of Social Work 16) Department of Sport Sciences \& Physical Education17) Department of Women Studies18) Center for South Asian Studies19) Center of Research Society of Pakistan 20) Pakistan Studies Center 21) College of Arts \& Design ). Because the study's population is so large, the researcher utilized multistage sampling to choose a sample. Multistage sampling refers to sampling plans where the sampling is carried out in stages using smaller and smaller sampling units at each stage. At the first stage, we selected five departments (Department of Sociology, Department of Mess Communication, Department of Administrative Sciences, Department of Physical Education, Department of History) out of the 21 departments through a simple random sampling using balloting (pick without replacement) technique. At the second stage, the researcher used the systematic sampling method to select a sample of 100 respondents from the total population of 5000 of the above 5 selected Departments (20 respondents from each Department). Systematic sampling is a probability sampling method where researchers select members of the population at a regular interval. The researcher chose the sample by selecting every 50th person on a list of the population in each department separately.

\section{Consideration and Approval of Ethical Issues}

Any research involving human participants requires moral approval to guarantee that the respect, rights, well-being, and prosperity of all partakers are prioritized throughout the study. To comply with the testing foundation's arrangements for human research, a request for moral endorsement was put forward to the research ethics committee through the Dean of student affairs. 
To all of them, the application consists of explaining the inquiry's points, the details of the surveys, the data that will be investigated through poll research, and how the data will be gathered, stored and retrieved afterward. The committee was also notified that the participants' privacy would be protected and that personal information, such as names, would not be included in the final analysis of the study. After a seven-day review by the committee, the head of the research ethics committee approved permission for the research to proceed.

\section{Results}

\section{Data Analysis}

SPSS statistical software was used to evaluate the survey data (i.e., the administered questionnaire), which displayed frequency counts and basic statistics in tables and figures. The overall system of the current examination has been circulated under four distinct classes, in particular; segment data, nature of web use, the impact of the web on scholastic execution and improving evaluations; and utilization of the web for upgrading general information. The appropriation of reactions gathered from understudies by directing a review that had been introduced as rate conveyance.

\section{Socio-Demographic Characteristics of the Respondents}

The demographic information included the analysis of the sample in terms of age, sex, and the number of places where the respondents had access to the internet. The demographic information of respondents is summarized in Table 1.

Table 1: Socio-Demographic Information

\begin{tabular}{|l|l|l|l|}
\hline Description & Frequency & \% \\
\hline \multirow{3}{*}{ Gender } & Male & 50 & $50.0 \%$ \\
\cline { 2 - 4 } & Female & 50 & $50.0 \%$ \\
\hline \multirow{2}{*}{ Class } & $20-23$ & 81 & $81.0 \%$ \\
\cline { 2 - 4 } & $24-26$ & 19 & $19.0 \%$ \\
\cline { 2 - 4 } & M.sc & 50 & $50.0 \%$ \\
\cline { 2 - 4 } & BS & 50 & $50.0 \%$ \\
\hline
\end{tabular}

The above table shows that from the sample of the total number of respondents Males made up half of the participants, while females made up the other half. Age distribution results of respondents in the various institutions show that only $19 \%$ of respondents were between the ages of 24 and 26, while the majority of respondents $(81 \%)$ were between the ages of 20 and 23. This could be due to the reason that only students in their first year were included in the study. The results showed that the participants came across five institutions. 50\% were students of MSc and 50\% of respondents were from BS. That shows an equal distribution from both classes. 


\section{Nature of Internet Usage}

The information about internet usage includes the analysis of samples in terms of their access to the internet; how long respondents are using the internet; use of the internet in a week; use of the internet in the number of hours and the purpose of the internet use.

Table 2: Percentage Distribution of Respondents Showing their Access to the Internet

\begin{tabular}{|c|c|c|}
\hline Where they have access to the internet & F & \% \\
\hline Dept. and home & 75 & $75.0 \%$ \\
\hline Dept. and hostel & 25 & $25.0 \%$ \\
\hline Total & 100 & $100.0 \%$ \\
\hline
\end{tabular}

The above Table 2 is based on the results of a quantitative survey of 100 students from five departments. It presents the responses of internet access participants. The results revealed that out of a sample of 100 respondents, $75 \%$ of respondents have internet access at home and in their department, and 25\% of respondents have internet access in their department and hostel. That shows all the respondents in the sample have complete internet access.

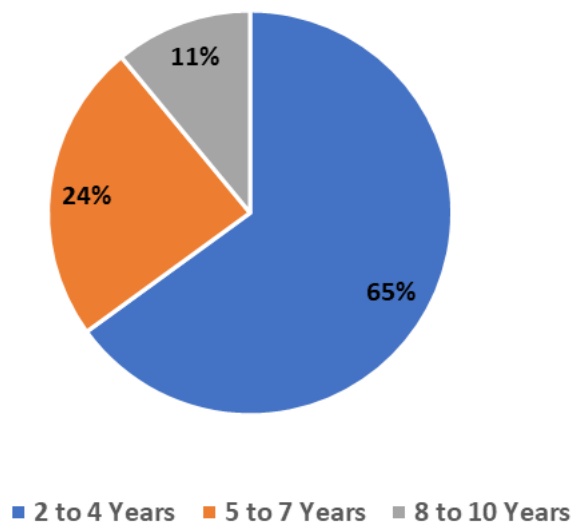

Figure 1: Percentage Distribution of Respondents Showing Since How Long Respondents are Using the Internet

Because of how long respondents have been using the internet, the above-mentioned Figure 1 shows that more than half $(65 \%)$ of the students claimed that they have been using the internet for two to four years, followed by (24\%) who were using it for the last 5 years, and $11 \%$ of respondents were using it for the last eight to ten years (see Figure 1). This data shows that all the respondents knew about the internet. None of the students reported that they do not use the internet. It was observed that most students were using the internet for two to four years. It may be because of the fast internet development in Pakistan. Due to this development in the last five years, people in Pakistan have easier access to the internet. 


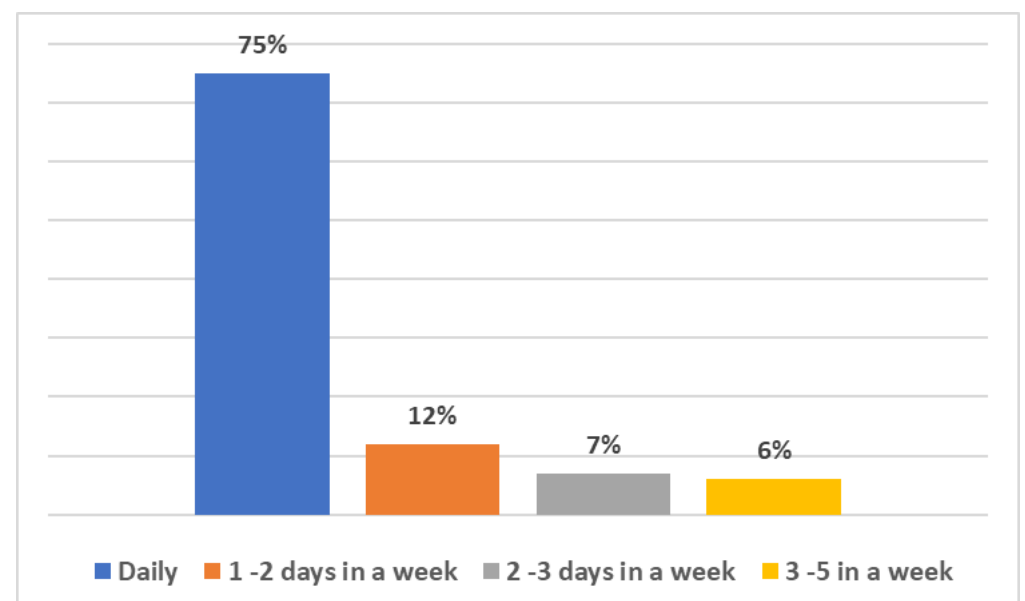

Figure 2: Percentage Distribution of Respondents Showing the Use of the Internet in a Week

In terms of determining the weekly frequency of internet usage among students, data from the five tested universities revealed that out of 100 students, the majority $(75 \%)$ used the internet daily, which could be owing to the unavailability of suitable internet facilities on campus or at home. $12 \%$ of the respondents were using the internet 1 to 2 days a week, $7 \%$ of the respondents were using the internet 2 to 3 days a week, and $6 \%$ of the respondents were using the internet 3 to 5 days a week. The above-mentioned Figure 2 shows that most students use the internet daily for academic purposes.

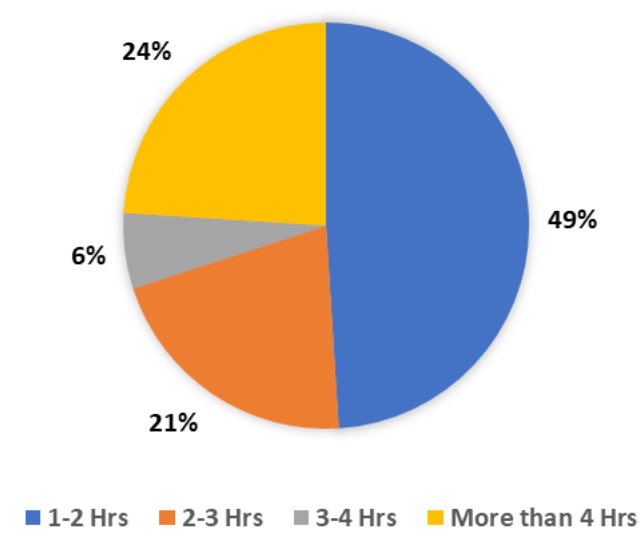

Figure 3: Percentage Distribution about the Number of Hours Usage of the Internet for Academic Purpose

The students asked about the number of hours used on the internet for academic purposes. The responses varied from up to one hour to five hours (see Figure 3). The analysis shows that out of a sample of 100 respondents, 
$49 \%$ of participants were using the internet from 1 to 2 hours a day and $21 \%$ of the participants were using the internet from 2 to 3 hours a day. $6 \%$ of participants were using the internet from 3 to 4 hours a day and $24 \%$ of participants were using the internet for more than 4 hours a day. The results from the above-mentioned Figure show that most students use the internet for 1 to 2 hours a day for academic purposes.

Figure 4 shows when students were asked to mention the purpose of internet use, $61 \%$ mentioned that they were using the internet for information and communication purposes, and $16 \%$ of respondents were using the internet for information and entertainment purposes, and $23 \%$ of respondents were using the internet for information, communication, and entertainment purposes. This data shows that most students were using the internet for information and communication purposes.

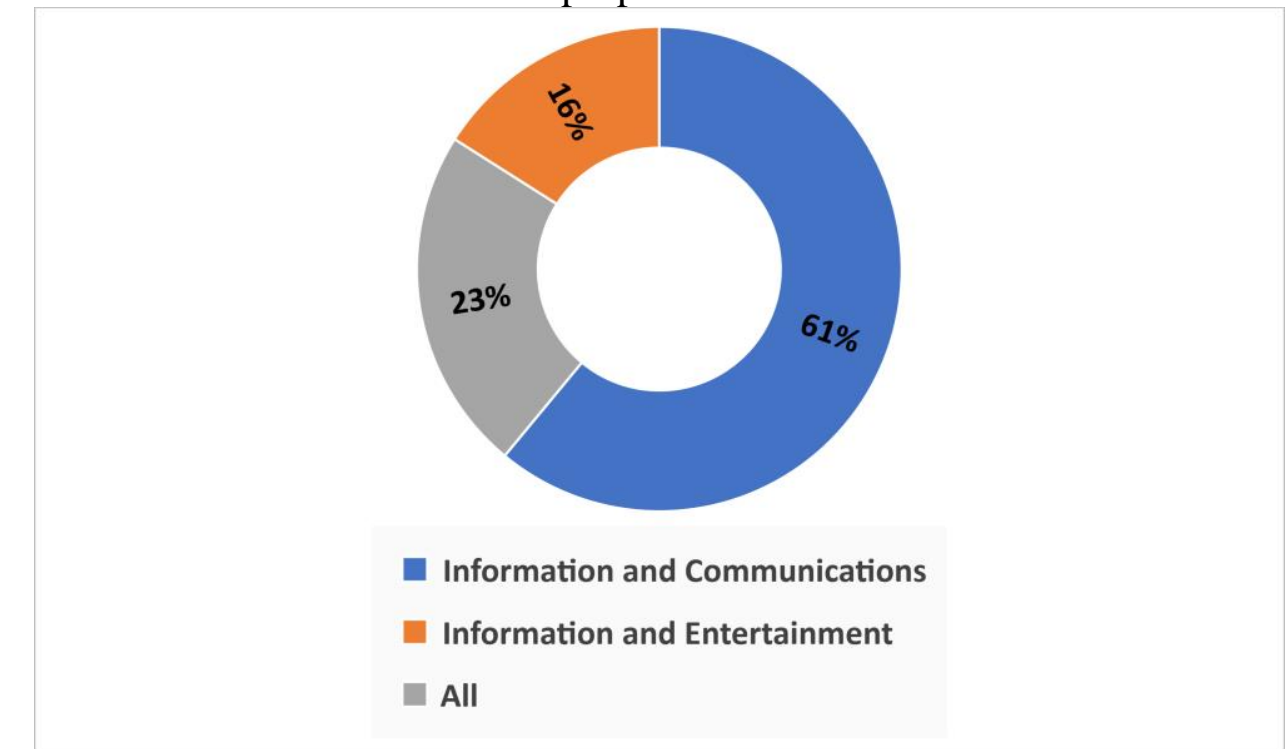

Figure 4: Percentage Distribution of Respondents Showing the Purpose of Internet Use

Impact of the Internet on Academic Performance and Improving Grades

The purpose of the present research is to explore the impact of the internet on academic performance and improving grades. The use of the internet has been widely accepted as a way of improving students' performance. The below-given questions were an attempt to see the impact of internet usage on academic performance and improving grades. 
Table 3: Percentage Distribution of Respondents Based on the Impact of Internet Use on Academic Performance and Improving Grades

\begin{tabular}{|l|l|l|l|}
\hline Categories & $\begin{array}{l}\text { To some } \\
\text { extent }\end{array}$ & $\begin{array}{l}\text { To great } \\
\text { extent }\end{array}$ & Not at all \\
\hline $\begin{array}{l}\text { (14) usage of the internet in improving students' } \\
\text { grades }\end{array}$ & $47 \%$ & $44 \%$ & $09 \%$ \\
\hline $\begin{array}{l}\text { (a) usage of the internet in the enhancement of } \\
\text { student learning }\end{array}$ & $42 \%$ & $57 \%$ & $01 \%$ \\
\hline $\begin{array}{l}\text { (b) Internet provides current and beneficial } \\
\text { material for studies }\end{array}$ & $31 \%$ & $68 \%$ & $01 \%$ \\
\hline $\begin{array}{l}\text { (c) Internet helps in advance preparation of class } \\
\text { lesson }\end{array}$ & $45 \%$ & $50 \%$ & $05 \%$ \\
\hline $\begin{array}{l}\text { (e) Use of internet to exposure the information } \\
\text { (h) Internet as an all-time available source }\end{array}$ & $32 \%$ & $59 \%$ & $09 \%$ \\
\hline $\begin{array}{l}\text { (i)Students who use the internet are better prepared } \\
\text { in their class than those who do not use }\end{array}$ & $36 \%$ & $63 \%$ & $04 \%$ \\
\hline $\begin{array}{l}\text { (n) Students who use the internet for study } \\
\text { purposes show promptness in delivering their } \\
\text { assignments }\end{array}$ & $44 \%$ & $49 \%$ & $07 \%$ \\
\hline $\begin{array}{l}\text { (o) Internet helps students with some questions } \\
\text { which a student cannot ask in the class }\end{array}$ & $36 \%$ & $60 \%$ & $04 \%$ \\
\hline $\begin{array}{l}\text { (q) Internet have positive relation regarding } \\
\text { educational purposes }\end{array}$ & $39 \%$ & $53 \%$ & $08 \%$ \\
\hline $\begin{array}{l}\text { (r) Online studies help to increase academic } \\
\text { performance }\end{array}$ & $36 \%$ & $53 \%$ & $11 \%$ \\
\hline (u) Internet is necessary for studies in modern age & $26 \%$ & $65 \%$ & $09 \%$ \\
\hline $\begin{array}{l}\text { (v) Students who take help from the internet for } \\
\text { their studies participate more in their class }\end{array}$ & $39 \%$ & $54 \%$ & $07 \%$ \\
\hline
\end{tabular}

The goal of the current study, as shown in Table 3, was to investigate the impact of internet use on academic performance and student grade improvement. The participants were University of the Punjab Lahore MSc and BS (Hons) students. The data shows that there is an impact of internet use on the academic performance of students. For example, Q_14a shows that the internet enhances students' learning by 57 percent, which is the majority of the respondents in the data. Q_14e shows that the internet proves useful for the exposure of information for 59 percent of students. That means the internet is a good source of information for the majority of students. Q_14o shows that the internet helps 60 percent of students with answering such questions which a student cannot ask in class. Q_14h shows that the internet is an all-time available source for 62 percent of the respondents that can help as an additional instrumental tool in improving grades. Q_14u shows that 65 percent of students' internet is necessary for improving grades. 
Table 4: Distribution of Students Grades and Confidence Level with Respect to Internet Access in the Last Exam

\begin{tabular}{|l|l|l|}
\hline Categories & Yes & No \\
\hline The students who access to internet & $70 \%$ & $30 \%$ \\
$-\quad 60-70 \%$ marks in exams & $13 \%$ & $19 \%$ \\
$-\quad 70-80 \%$ marks in exams & $19 \%$ & $06 \%$ \\
$-\quad$ Above 80\% marks in exams & $38 \%$ & $05 \%$ \\
\hline Measurement of confidence level & $83 \%$ & $17 \%$ \\
\hline
\end{tabular}

The above Table 4 indicates the previous academic record of the respondents to know the academic achievement in their last exams. The Table shows how much the internet affected the grades of students. This is the comparison between students who have access to the internet or not, and how much it affected their grades. For this researcher collected the records of different respondents. $70 \%$ of the respondents had access to the internet in their last exams and 30\% of respondents had no access to the internet. The majority of the respondents' range was above $80 \%$ who used the internet in the last exams, while the $05 \%$ of respondents who did not use the internet in the last exams. $83 \%$ of respondents agreed that their confidence level was positively high after using the internet. The results showed that the academic achievement of the students who used the internet in their last exams was very high as compared to those who did not use the internet in their last exams.

Table 5: Academic Performance of Students who Used the Internet in Last Exams

\begin{tabular}{|c|c|}
\hline Above average & $35 \%$ \\
\hline Average & $61 \%$ \\
\hline Below average & $4 \%$ \\
\hline
\end{tabular}

The above Table 5 indicates that the students who used the internet in their last exams their percentage was very high. $61 \%$ of the respondents lie on the average level in the class and $35 \%$ of respondents were on above average. The results strongly showed that the performance level of the students was high in the class by using the internet in their last exams.

\section{Use of the Internet for Enhancing General Knowledge}

The aim of the present research was also to see the impact of the internet on the enhancement of general knowledge. The purpose of the belowmentioned Table 6 is to show the academic performance of students in getting information and in enhancing general knowledge. Students use other helpful materials to improve their performance in class and enhance their grades. The findings indicate that 56 percent of the respondents strongly agreed that the internet can substitute for books and magazines. 50 percent of the respondents 
strongly agreed that the internet is another source that provides greater knowledge about current affairs.

Table 6: Percentage Distribution of Respondents Based on Internet Use for Enhancing

\begin{tabular}{|c|c|c|c|}
\hline \multicolumn{4}{|l|}{ General Knowledge } \\
\hline Categories & $\begin{array}{c}\text { To some } \\
\text { extent }\end{array}$ & $\begin{array}{c}\text { To } \\
\text { great } \\
\text { extent }\end{array}$ & $\begin{array}{c}\text { Not at } \\
\text { all }\end{array}$ \\
\hline (d) Internet can substitute for the books and magazines & $39 \%$ & $56 \%$ & $5 \%$ \\
\hline $\begin{array}{l}\text { (k) The internet provides greater knowledge about } \\
\text { current affairs }\end{array}$ & $47 \%$ & $50 \%$ & $3 \%$ \\
\hline (f) Internet use reduces the dependency of teacher & $41 \%$ & $39 \%$ & $20 \%$ \\
\hline $\begin{array}{l}\text { (g) Internet more helpful than the teacher in solving } \\
\text { students' problems }\end{array}$ & $35 \%$ & $42 \%$ & $23 \%$ \\
\hline (m) Internet creates a gap between teacher and student & $37 \%$ & $41 \%$ & $22 \%$ \\
\hline
\end{tabular}

Where the internet is a source of knowledge, it has also reduced the dependency on teachers. $41 \%$ of respondents to some extent agreed and 39 percent of respondents strongly agreed that the internet is reducing the dependency of teachers on any particular topic. The majority of the respondents strongly agreed that the internet is a more helpful instrument than teachers who solve the problems of students regarding studies, which is creating a gap between students and teachers. $41 \%$ of the respondents strongly agreed that the internet is the cause of the gap between students and teachers. The above table indicates that the internet is an additional source of information and knowledge and has made students independent.

\section{Discussion}

The present study aimed to find out if there is any significant relationship between internet usage and academic performance or in improving their grades. It is assumed that students who use the internet for academic purposes have better academic performance and higher grades. This study based on the hypothesis was defined in this manner. As people interact more with the internet and utilize material from the internet, they have more chances of attaining good marks in the examination.

The following was the actual statement that showed the research hypothesis: "The more the use of the internet for academic purposes, the higher the level of academic performance of students."

The researchers concluded that there was a positive impact of internet use on the academic performance of students. The research hypothesis has been proved through calculated findings from the collected data. Homan's theory of social interaction supposed the findings of the present study that the frequency of interaction with the internet leads to liking and creating sentiments to use the internet. In this way, students will use the internet more 
for study purposes, and this will lead to high academic performance or grades from the collected data. Homan's theory of social interaction supposed the findings of the present study that the frequency of interaction with the internet leads to liking and creating sentiments to use the internet. In this way, students will use the internet more for study purposes and this leads to high academic performance or grades.

Except for seeing the impact of internet use on the academic performance of students, the researchers also found some new aspects of the topic that need to be addressed in future research. A question was asked in research: "Is the internet a cause of mental and physical disorder among students?" and data analysis shows that out of the sample of 100 respondents, 68 percent of students think that the internet can become the cause of mental and physical disorder among students, which is another problem. There is a need to conduct some future research on this topic. Another finding during the analysis was that 86 percent of students think that without using the internet, they may not be able to show good academic performance. This means the internet is necessary for most students to continue their good academic performance. This topic also needs the attention of future researchers. The analysis also shows that 80 percent of the respondents think that the internet plays an important role in increasing their social networking. That is also a new aspect of research. Today, the world is a global village and technology is the basis of this globalization. In this modern world, most people think that internet technology is important for their success. The present study also shows that 67 percent of respondents think that the continuous use of the internet may become the cause of internet addiction for students and they may not be able to improve their grades or academic achievements without using the internet.

\section{Conclusion}

After going through the whole study, the researchers reached the following conclusions; 1 ) There is a significantly positive relationship between the level of internet usage and the level of academic performance of students; 2) The study was conducted in the framework of Homan's theory of interaction. The findings of the study showed positive changes in the learning process; 3 ) The results showed that the academic performance of the students greatly increased after using the internet; 4 ) The researchers also came to know that the internet reduced the dependency of teachers. The result showed that there is a strong gap between the student and teacher relationship; 5) A majority of the respondents agreed that the additional source helped to enhance their academic performance and learning; 6) The majority of the respondents positively responded that the internet helped in the preparation of advanced lectures and assignments; 7) Most of the respondents agreed that students who 
used the internet have greater knowledge of current affairs; 8) The research hypothesis was supported by the results of Chi-square, i.e., it was accepted. The above points show that the focus of the study was that students were empowered to improve their academic performance by using the internet. Similar findings were given by Apuke et al. (2018) that university students regarded internet use to have a favorable effect on their academic research and learning; Shahibi et al. (2017) also discovered that internet usage is significant in affecting a student's academic performance.

\section{Recommendations}

In the light of the whole study, the researchers proposed the following suggestions: The researcher conducted the research only at Punjab University's new campus while further researches can be conducted at other universities and different colleges and schools. The researchers further suggested that the impact of the internet should not only be applied on the academic level, it also should be applied to other sociological and psychological aspects of life. The study recommended that Students should extend their internet usage outside their homes to take the optimum advantage from using the internet and the University should increase the number of computers in the labs and provide the facility of internet according to the needs to meet the students' population of the department of Punjab University.

\section{References:}

1. Abaido, G. M. (2020). Cyberbullying on social media platforms among university students in the United Arab Emirates. International Journal of Adolescence and Youth, 25(1), 407-420.

2. Ahmed, I., \& K. A. P. (2011). Mobile Phone to Youngsters: Necessity or Addiction. Information Management and Business Review, 2(5), 229-238.

3. Al-Rahmi, W., \& Othman, M. (2013). The impact of social media use on academic performance among university students: A pilot study. Journal of Information Systems Research and Innovation, 4(12), 1-10.

4. Apuke, O. D., \& Iyendo, T. O. (2018). University students' usage of the internet resources for research and learning: forms of access and perceptions of utility. Heliyon, 4(12).

5. Asdaque, M. M., Khan, M. N., \& Rizvi, S. A. A. (2010). Effect of internet on the academic performance and social life of university students in Pakistan. Journal of Education and Sociology, 4(3), 21-27.

6. Baruah, T. D., \& Hazarika, J. (2020). Use of Mass Media Tools for Effective Social and Behaviour Change Communication. Krishna Kanta Handiqui State Open University. 
7. Bryant, J.A., Sanders-Jackson, A., and Smallwood, A. (2006). Iming, text messaging, and adolescent social networks. Journal of ComputerMediated Communication, 11(2), 577-592.

8. Desmal, A. J. (2017). The impact of using social media and internet on academic performance case study Bahrain Universities. ICST Transactions on Scalable Information Systems, 4(13).

9. Dramanu, B. Y., \& Balarabe, M. (2013). Relationship between academic self-concept and academic performance of junior high school students in Ghana. European Scientific Journal, 9(34).

10. Eguavoen, E. O. (2016). ICT utilization as correlates of academic performance among students with visual impairment in Lagos state, Nigeria. European Scientific Journal, 12(13).

11. Flad, K. (2010). The influence of social networking participation on student academic performance across gender lines.

12. Ghasempour, M., \& Jarideh, S. (2014). The impact of computer and information communication technology literacy on the academic achievement of medical and dental Students at shiraz university of medical sciences. European Scientific Journal, 10(9).

13. Greenfield, P. and Subrahmanyam, K. (2008). Online communication and parental involvement. The Future of Children, 18(1),119-140

14. Habes, M., Alghizzawi, M., Khalaf, R., Salloum, S. A., \& Ghani, M. A. (2018). The relationship between social media and academic performance: Facebook perspective. International Journal of Information Technology and Language Studies, 2(1), 12-18.

15. Harrath, Y., \& Alobaidy, H. (2016). Impact of Social Networking Sites on Student Academic Performance: The Case of University of Bahrain. Journal of Cases on Information Technology , 18(2), 35-50.

16. Heather Kanuka, (2002). A Principled Approach to Facilitating Distance Education: The Internet, Higher Education and Higher Levels of Learning. Journal of Distance Education, 17(2), 70-86.

17. Hussain, I. (2012). A study to evaluate the social media trends among university students. Procedia - Social and Behavioral Sciences, 64, 639-645.

18. Kirschner, P. A., \& Paas, F. (2001). Web-enhanced higher education: a tower of Babel. Computers in Human Behavior, 17(4), 347-353.

19. Kolikant, Y. B. D. (2010). Digital natives, better learners? Students' beliefs about how the Internet influenced their ability to learn. Computers in Human Behavior, 26(6), 1384-1391.

20. Laird, T. F. N., \& Kuh, G. D. (2005). Student experiences with information technology and their relationship to other aspects of student engagement. Research in Higher education, 46(2), 211-233. 
21. Laurillard, D. (1992). Learning through collaborative computer simulation. British Journal of Educational Technology, 23(3), 164171.

22. Merten, M. and Williams, A. (2009). Adolescents' online social networking following the death of a peer. Journal of Adolescent Research, 24, 67-90.

23. Mesch, G. (2009). Parental mediation, online activities, and cyberbullying. CyberPsychology and Behavior, 12(4), 387-392.

24. Mesch, G. S. (2018). Parent-child connections on social networking sites and cyberbullying. Youth \& Society, 50(8), 1145-1162.

25. Miller, D. (2020). Social networking sites. Digital Anthropology, 146161.

26. Mwanza, R., \& Musyoka, L. (2018). Principals' Instructional Supervision Practices: Key to Kiswahili Academic Performance. European Scientific Journal, 14(28).

27. Peter, J. and Valkenburg, P. (2009). Social consequences of the internet for adolescents: A decade of research. Psychological Science, 18(1).

28. Rabiu, H., Muhammed, A. I., Umaru, Y., \& Ahmed, H. T. (2016). Impact of mobile phone usage on academic performance among secondary school students in Taraba State, Nigeria. European Scientific Journal, 12(1).

29. Shabir, G., Hameed, Y. M. Y., Safdar, G., \& Gilani, S. M. F. S. (2014). The impact of social media on youth: A case study of Bahawalpur city. Asian Journal of Social Sciences \& Humanities, 3(4), 132-151.

30. Shahibi, M. S., \& Rusli, K. N. (2017). The influence of internet usage on student's academic performance. International Journal of Academic Research in Business and Social Sciences, 7(8), 873-887.

31. Warren, A., Brunner, D., Mair P., \& Barnet, L. (1998). Technology in Teaching and Learning: An Introductory Guide. Kogan Page.

32. Yang, H. L., \& Tang, J. H. (2003). Effects of social network on students' performance: A web-based forum study in Taiwan. Journal of Asynchronous Learning Networks, 7(3), 93-107. 